\title{
Redesign your in-person course for online: creating connections and promoting engagement for better learning.
}

\author{
Nicole Theodosiou ${ }^{1}$ and Jeff Corbin ${ }^{1}$ \\ ${ }^{1}$ Union College
}

July 2, 2020

\begin{abstract}
This spring, instructors moved their courses online in an emergency fashion as campuses were closed due to the pandemic. As colleges prepare for the next academic year, there is a need to provide flexible instruction that is more intentional for quality online learning. We taught two undergraduate courses online for the first time this spring and surveyed our students' reactions to the course experiences. From our experiences and student feedback we identified design elements and activities that were beneficial in promoting student engagement, sense of connectivity, and learning. We describe four qualities for a successful transition to online learning: 1) big questions and core concepts; 2) peer groups including reflective writing; 3) outreach to broader scientific community; and 4) instructor's social presence in the class. Our experience gives us confidence that courses can be redesigned for online without compromising rigor or essential learning goals.
\end{abstract}

\section{Hosted file}

Theodosiou and Corbin - Redesigning your in person course for online.pdf available https://authorea.com/users/339089/articles/465362-redesign-your-in-person-course-foronline-creating-connections-and-promoting-engagement-for-better-learning

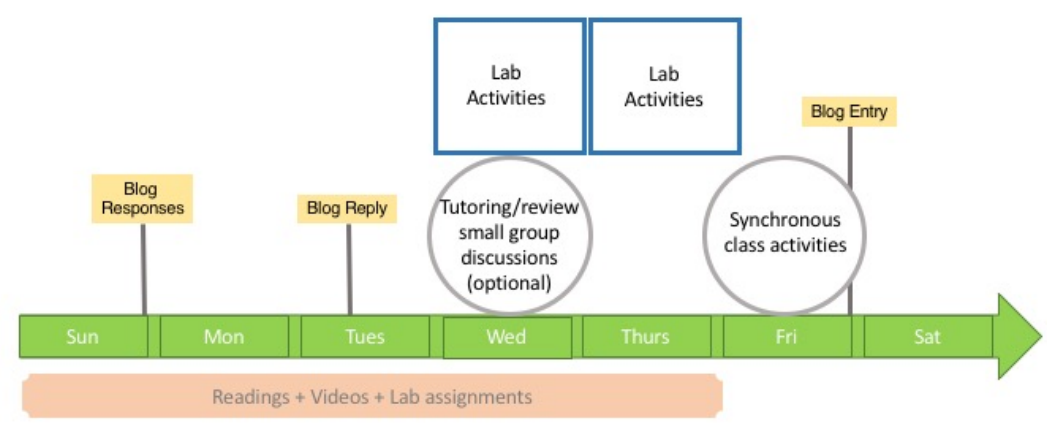



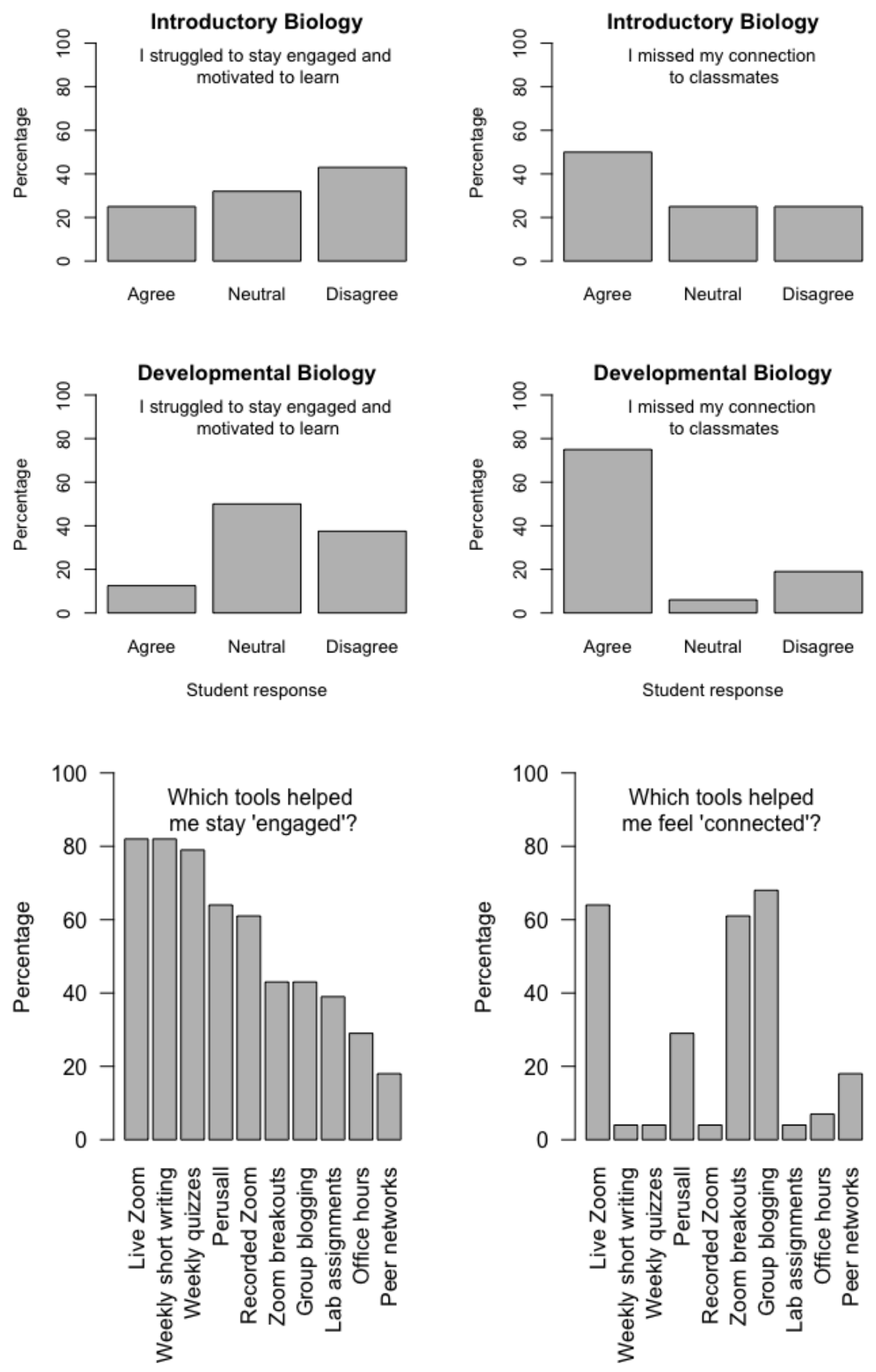

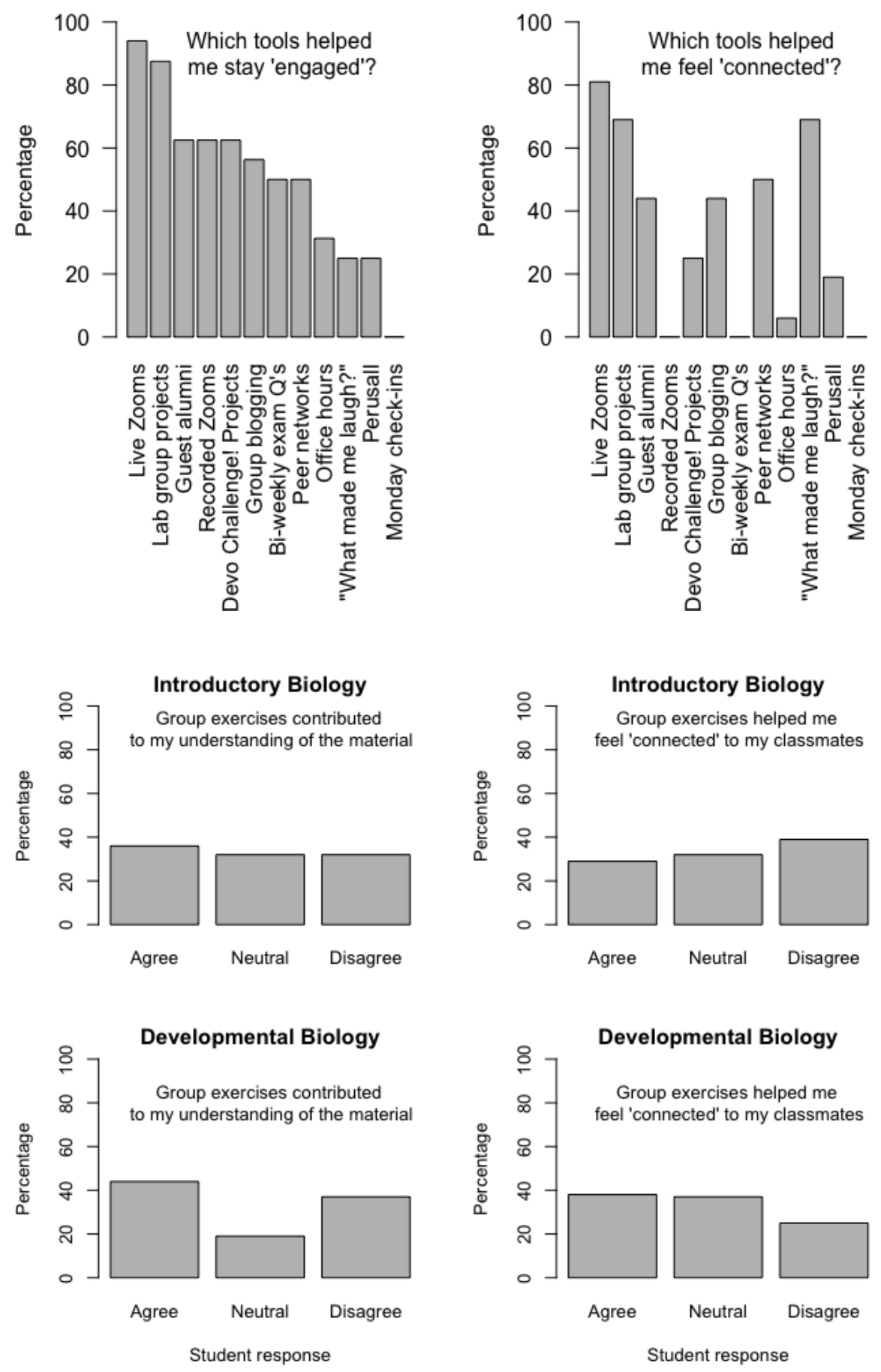